\title{
Structural and Ultra-Structural Features of the First Mandibular Molars of Young Rats Submitted to Pre and Postnatal Protein Deficiencies
}

\author{
L.A. Gonçalves, S.C. Boldrini*, T.S.O. Capote, C.B. Binotti, R.A. Azeredo, D.T. Martini, \\ B. Rosenberg, W.G. Bautz and E.A. Liberti*
}

Department of Anatomy, Biomedical Sciences Institute, University of Sao Paulo, Brazil

\begin{abstract}
The effects of protein malnutrition, both in utero and prior to weaning, on formation of the first mandibular molars were evaluated by phase-contrast and electron microscopy in rats. The nourished group (GI) received a diet that included $20 \%$ casein, while the malnourished group (GII) received 5\% casein. The first mandibular molars from GII exhibited low density of cells and odontoblasts, which lacked regular organization compared with molars from GI. In addition, a difference in collagen type was observed between the groups, with a prevalence of Type III collagen fibers detected in the dentin, periodontal ligament, and alveolar bone of GII, and a prevalence of Type I collagen fibers in GI. Finally, examination of surface area in molar sagittal sections indicated $30 \%$ less dentin in GII, compared with GI. Our results suggest that structural and ultra-structural features of the dentin-pulp complex and periodontal components of rat molars are affected by protein deficiency.
\end{abstract}

Key Words: Protein malnutrition, rat, molar tooth, collagen fibers, electron microscopy.

\section{INTRODUCTION}

Nutritional protein deficiency can affect multiple tissues, organs, and systems [1-4]. In mineralized structures, such as bone, protein deficiency can lead to a delay in the appearance of ossification centers as well as a decrease bone width [5-8]. Nonetheless, the length of long bones, which exhibit extended growth, are less affected by nutritional insult [3].

For teeth, disturbances in diet during enamel and dentin formation lead to changes in the chemical composition, cellular structure, and consequently appearance, of the teeth [9], and the relationship between tooth size and morphology and tooth development and maturation has been previously described [10]. Importantly, malnutrition can lead to a delay in dental eruption [11-15] and an increase in susceptibility to development of caries [11,16-18]. Dental germs of rats submitted to protein deficiency exhibited weight reduction, lower calcium levels [19], and a substantial decrease in collagen synthesis [20]. Fluoride deficiency in rats maintained on a low-protein diet increased enamel deposition by $48 \%$ and decreased dentin by $28 \%$ [21]. Moreover, reduced dentin formation was observed among rats submitted to a proteindeficient diet [22]. Recently, the effects of undernutrition on enamel defects in socio-economically underprivileged communities have begun to be appreciated [23].

Given these descriptive studies of the effects of malnutrition on dental structure, we here aimed to evaluate structural and ultra-structural features of mineralized dental tissues, the dentin-pulp complex, and periodontal structures, as well as

*Address correspondence to these authors at the Department of Anatomy, Biomedical Sciences Institute, University of Sao Paulo, Brazil; Tel: +55-113091-7226; Fax +55-11-3091-7366; E-mails: sboldrin@usp.br and

ealibert@icb.usp.br the sectional area of dentin in molars from rats submitted to pre and postnatal protein deficiencies.

\section{MATERIALS AND METHODOLOGY}

Experiments were conducted according to Ethical Principles in Animal Research adopted by the Brazilian College of Animal Experimentation (COBEA). Young male and female Wistar rats (200-240 g body weight) were mated for seven to ten days. After conception, females were placed in individual cages and were maintained under standard conditions at $21^{\circ} \mathrm{C}$, with a $12 \mathrm{~h}$ light-dark cycle. During gestation, rats were given ad lib access to water and to AIN-93G purified rodent diet [24]. The diets for the control or nourished (GI) and malnourished (GII) groups contained 20\% and 5\% content of casein, respectively (Rhoster, SP, Brazil). Following birth, dams and pups of both groups, received respective diets until weaning (21 days).

Five male pups from both GI and GII groups were killed by intraperitoneal injection of 3\% hypnol. The soft tissues surrounding the mandibles were dissected, and were sectioned along the midline. Right and left hemi-mandibles from each specimen were immersed for fixation in Bouin solution for 48 hours, washed in running water for 18 hours, and maintained in fixative solution of $(50 \%$ formic acid and $20 \%$ sodium citrate) [25]. After dehydration through an increasing alcohol series, specimens were embedded in paraplast (Histologie Histosec - Merck). Sagittal serial sections of $6 \mu \mathrm{m}$ were obtained from hemi-mandibles, and were stained with Hematoxilin-eosin by Masson's technique. Samples were also using the Picro-sirius method [26], and were examined under polarized light.

For scanning electron microscopy (SEM), mandibles from five male pups from each group were obtained, dis- 
sected as previously described, and immersed in a modified solution of Karnovsky solution (2.5\% glutaraldehyde and $2 \%$ paraformaldehyde in $0.1 \mathrm{M}$ sodium phosphate buffer, $\mathrm{pH}$ 7.3) for 24 hours at $4^{\circ} \mathrm{C}$. After sectioning along the midline, right and left hemi-mandibles from each specimen were immersed in a $0.5 \%$ sodium hypochlorite solution for 3 days, washed in distilled water, and dehydrated through an increasing alcohol series. Specimens were then dried using a $\mathrm{CO}_{2}$ critical point device, mounted on aluminum stubs with conductive glue, gold sputtered, and then examined by SEM (Jeol, JSM-6100). The right first lower molar from three animals from each group were prepared for transmission electronic microscope (TEM). These were immersed in a fixative solution $(2.5 \%$ glutaraldehyde and $0.2 \%$ tannic acid). After centrifugation for $30 \mathrm{~min}$, specimens were again fixed in glutaraldehyde/tannic acid for 2 hours, and then immersed in a decalcifying solution (50\% formic acid and $20 \%$ sodium citrate). Specimens were embedded in araldite using standard procedures and examined by TEM (Phillips EM301 electron-microscope).

Morphometric analysis of hemi-mandibles from both groups was performed using hematoxylin-eosin staining. The Axiovision system (Zeiss) was used to make internal and external dentin surface drawn. Mean dentin surface areas in sagittal sections (in $\mathrm{mm}^{2}$ ) for the first lower molars from both groups was determined using a morphometric method [27]. Data were analyzed by Student's t-test ( significance $=\mathrm{p}$ $<0.05)$.

\section{RESULTS}

\section{Phase-Contrast Microscopic Examination of Molars}

We examined dentin in the first molars from animals submitted to normal and low protein diets. In animals from GI, the control group, a thick odontoblastic palisade was observed lining the dentin in the radicular region of the first molars. Near the pulpar cavity, a narrow cell-free and a welldefined inner zones rich in fibroblasts and mesenchymal cells were also observed (Fig. 1A). In contrast, in GII first molars, the odontoblastic palisade was not observed, nor could a cell-free zone be detected (Fig. 1B).

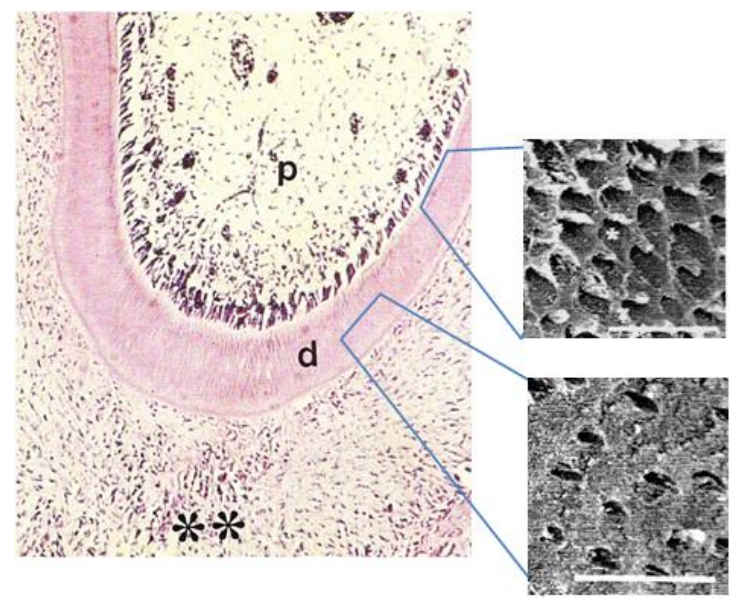

Fig. (1A). Photomicrograph of rat molars. Radicular region of GI molar showing the dental pulp (p), dentin (d) and periodontum (**). Odontoblastic palisade lining the dentin (Calibration bar: $50 \mu \mathrm{m}$ ). SEM reveals three-dimensional features including circumpulpal and peripheral dentin with dentinal tubules (*). (Calibration bar: $10 \mu \mathrm{m})$.

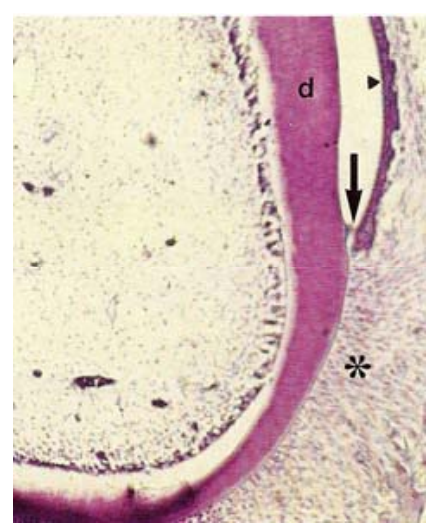

Fig. (1B). Photomicrograph of rat molars. In GII molars, no odontoblastic palisade or cell-free zone was observed. Note in the gingival sulcus, the sulcular epithelium (arrowhead) and loss of epithelial adhesion (arrow) within the junctional epithelium (HE, Calibration bar: $50 \mu \mathrm{m})$.

Pulp tissue, which is well organized and highly cellularized in molars from GI, exhibited broad hollow spaces in the first molars of GII animals (Fig. 2A, B). At high magnification, the more densely organized cellular components in the pulp of nourished animals (GI) was apparent (Fig. 2C, D).

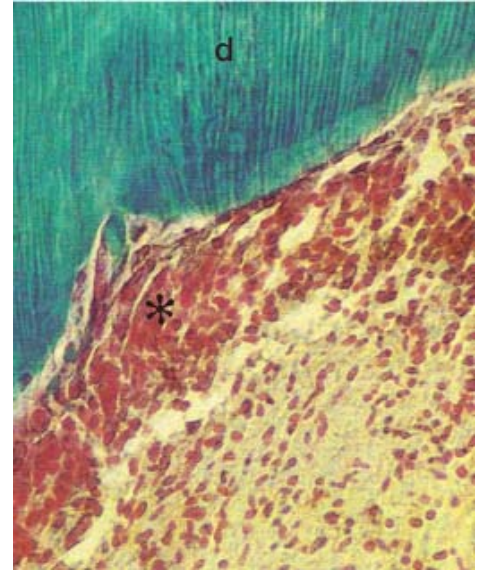

Fig. (2A). Photomicrograph of rat molars. In GI molars, dentin (d) with parallel dentinal tubules are detected, and dental pulp (*) cellular elements appear highly organized (Tricromo Masson, Calibration bar: $50 \mu \mathrm{m})$.

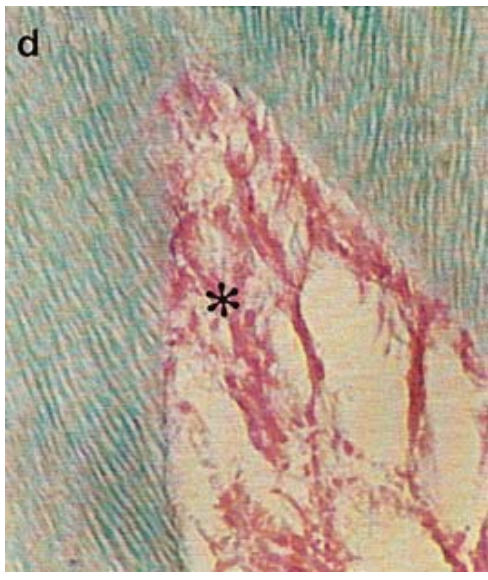

Fig. (2B). Photomicrograph of rat molars. In GII molars, parallel dentinal tubules (d) are accompanied by retracted pulp (*) with wide interior spaces (Tricromo Masson, Calibration bar: $50 \mu \mathrm{m}$ ). 


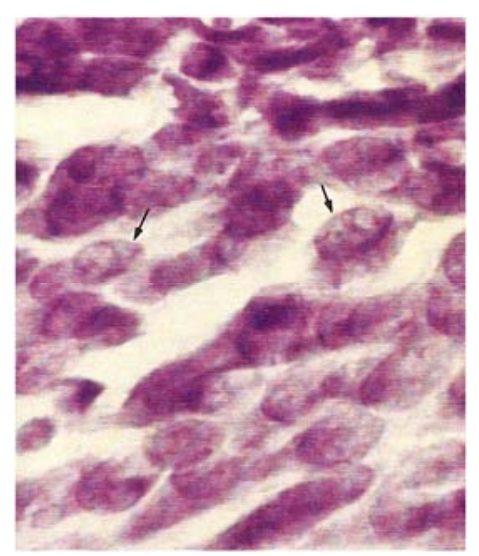

Fig. (2C). Photomicrograph of rat molars. In GI molars, fibroblasts are detected within the central pulp, and exhibit granular cytoplasm and an eccentric nucleus (arrows) (HE, Calibration bar: $20 \mu \mathrm{m}$ ).

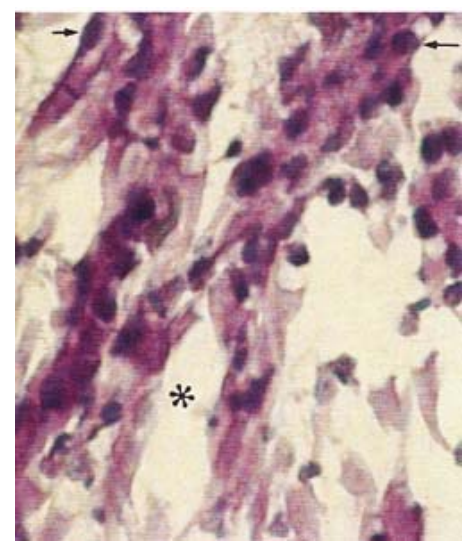

Fig. (2D). Photomicrograph of rat molars. In GII molars, broad spaces are detected within the central pulp (*), and fibroblasts exhibit irregular morphology, with retracted and intensely stained nuclei (arrow) (HE, Calibration bar: $20 \mu \mathrm{m}$ ).

In the gingival sulcus of molars of GI, the junctional epithelium exhibited well-defined cell outlines that were not be observed in GII molars. In contrast, a loss of epithelial adherence was evident in GII molars (Fig. 1B, 3A, B). Densely arranged fibroblasts were present in the periodontal ligament of mandibles from GI. These cells exhibited elongated, parallel nuclei that were oriented in the same direction as the collagen fibers within the ligament (Fig. 3A, C). In GII, fibers lacked regular organization, and the contours of the fibroblasts nuclei were not well delineated (Fig. 3D).

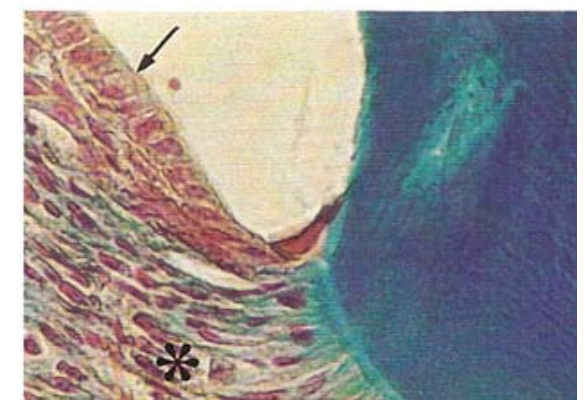

Fig. (3A). Photomicrograph of the periodontal region of rat molars. Within GI molars, dense areas of the periodontal ligament $\left(^{*}\right)$ appeared rich in fibroblasts and distinct layers were evident within the junctional epithelium (arrow) (Tricromo Masson, Calibration bar: $50 \mu \mathrm{m})$.

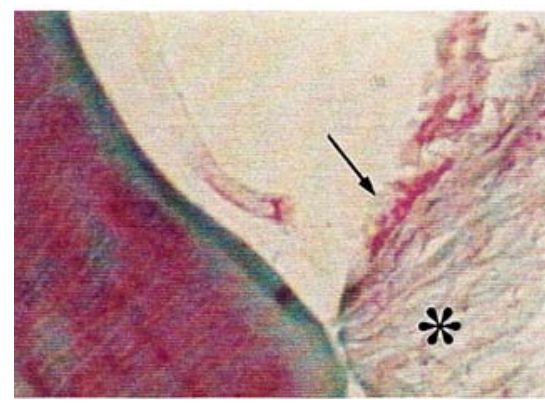

Fig. (3B). Photomicrograph of the periodontal region of rat molars. Within GII molars, the periodontal ligament $(*)$ stained weakly, and few fibroblasts were detected. In addition, few cellular layers were detected within the junctional epithelium (arrow) (Tricromo Masson, Calibration bar: $50 \mu \mathrm{m}$ ).

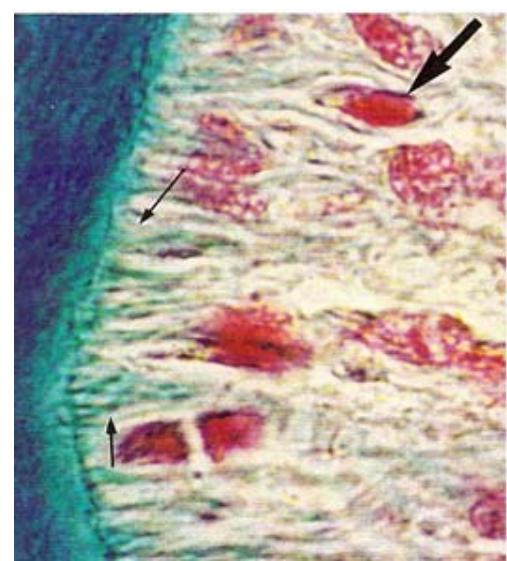

Fig. (3C). Photomicrograph of the periodontal region of rat molars. Within GI molars, fibroblasts within the periodontal ligament (larger arrows) are arranged in parallel in the direction of the collagen fibers (larger arrows) (Tricromo Masson, Calibration bar: 10 $\mu \mathrm{m})$.

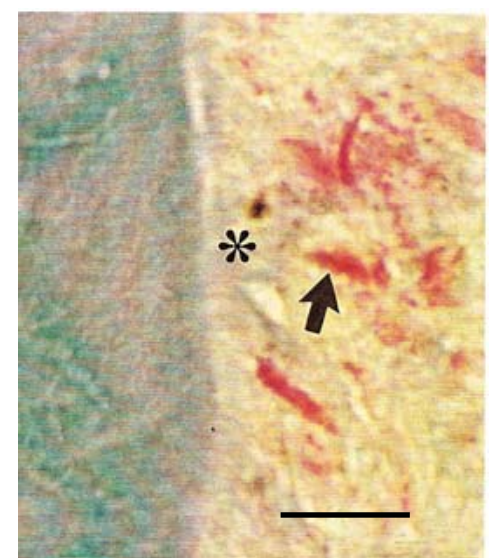

Fig. (3D). Photomicrograph of the periodontal region of rat molars. Within GII, collagen fibers appear disorganized $(*)$, and weakly stained fibroblasts with indistinct nuclei (arrow) were detected (Tricromo Masson, Calibration bar: $10 \mu \mathrm{m}$ ).

Analysis of sections stained with the Picro-sirius method under polarized light allowed observation of dentin, periodontal ligaments, and alveolar bone regions in both groups. Within GI Type I collagen fibers were almost exclusively detected (red, orange and yellow). In the corresponding regions of GII, in spite of the presence of Type I collagen fibers in dentin, Type III collagen fibers were clearly pre- 
dominant (green). In addition, the trabecular structure of the alveolar bone in GI was thicker than in GII, with a predominance of Type I collagen fibers detected in GI (Fig. 4E, F).

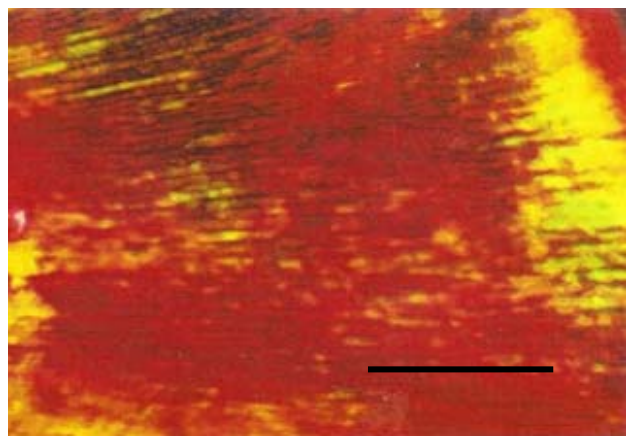

Fig. (4A). Photomicrograph of rat molar under polarized light. Within GI molars, mainly Type I collagen fibers are detected in the dentin (Picro-sirius, Calibration bar: $50 \mu \mathrm{m}$ ).

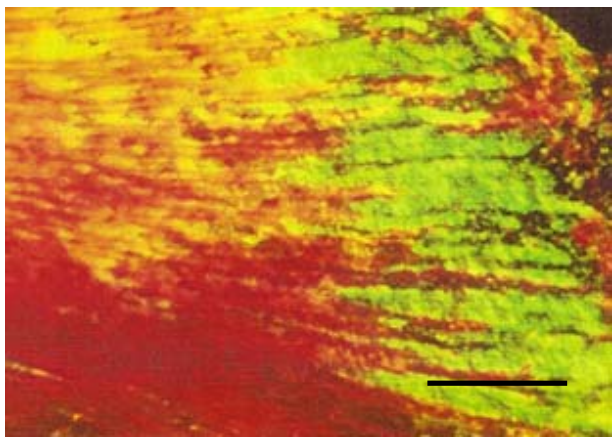

Fig. (4B). Photomicrograph of rat molar under polarized light. Within GII molars, Types I and III collagen fibers are detected in the dentin (Picro-sirius, Calibration bar: $50 \mu \mathrm{m}$ ).

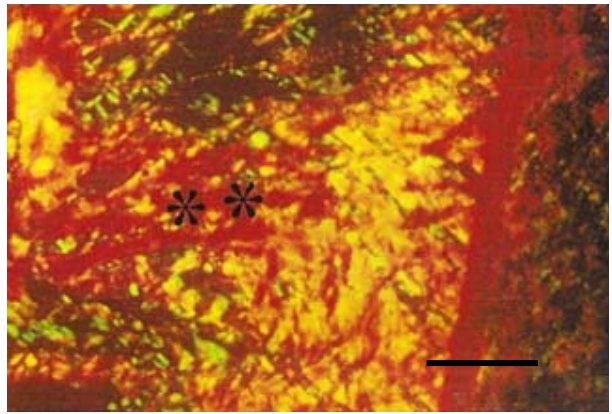

Fig. (4C). Photomicrograph of rat molar under polarized light. Within GI periodontal ligaments, mainly type I are detected (**) (Picro-sirius, Calibration bar: $50 \mu \mathrm{m}$ ).

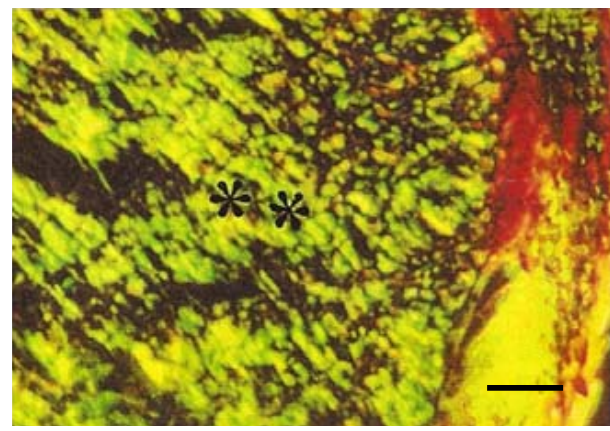

Fig. (4D). Photomicrograph of rat molar under polarized light. Within GII periodontal ligaments, mainly Type III collagen fibers are detected $(* *)$ (Picro-sirius, Calibration bar: $50 \mu \mathrm{m})$.

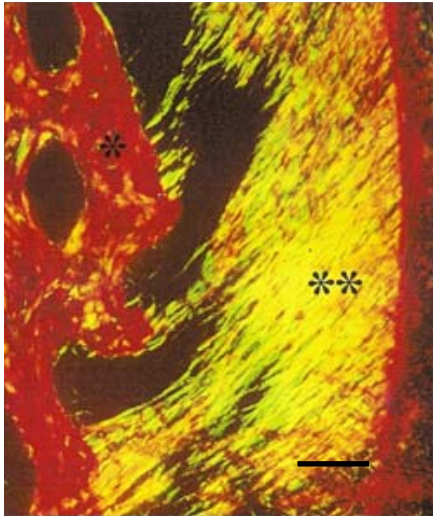

Fig. (4E). Photomicrograph of rat molar under polarized light. Within GI, predominantly Type I collagen fibers are detected in the periodontal ligament $(* *)$ and alveolar bone $(*)$ (Picro-sirius, Calibration bar: $50 \mu \mathrm{m})$.

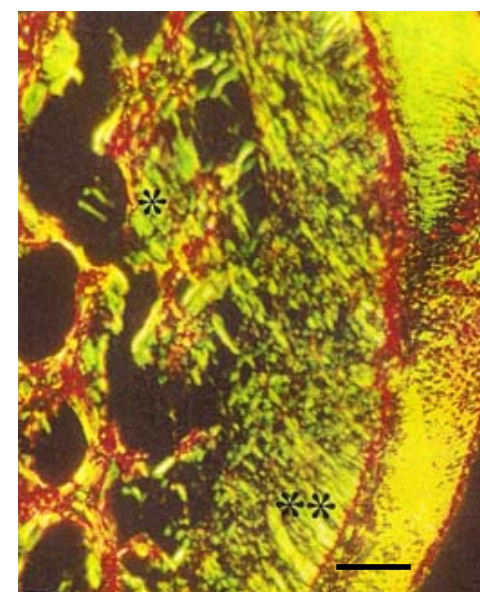

Fig. (4F). Photomicrograph of rat molar under polarized light. Within Photomicrography of rat molar under polarized light. GII, Type III collagen fibers are mainly detected in periodontal ligament $(* *)$ and alveolar bone (*) (Picro-sirius, Calibration bar: $50 \mu \mathrm{m}$ ).

\section{Electron Microscopic Examination of Molars}

By SEM, different regions of the dentin, including the circumpulpal and peripheral dentin regions were evident (Fig. 1A), yet no differences were observed between the two groups. By TEM, collagen fibrils oriented in different directions formed a dentin supporting structure in GI. These appeared relatively thick and densely arranged, and surrounded the openings of the dentinal tubules in a concentric manner (Fig. 5A). In GII, a clear reduction in both the diameter and the density of the collagen fibrils was observed, and fibrils lacked a concentric arrangement surrounding the openings of the dentinal tubules (Fig. 5B). Moreover, in GI, the odontoblastic process exhibited a higher density and homogeneity when compared to GII (Fig. 5C, D). Few fibrils were detected in the periodontoblastic space in both groups (Fig. 5AD).

\section{Measurement of Dentin Sagittal Sectional Surface Area}

To quantify differences in dentin between the experimental groups, mean surface areas of molar sagittal sections were measured. Mean values ( \pm standard deviation) were, $1.38 \pm$ $0.29 \mathrm{~mm}^{2}$ for GI and $0.96 \pm 0.19 \mathrm{~mm}^{2}$ for GII, indicating $30 \%$ 
less dentin in molars from GII (Fig. 6). Statistical analysis revealed that this difference was significant $(\mathrm{p}=0.018)$.

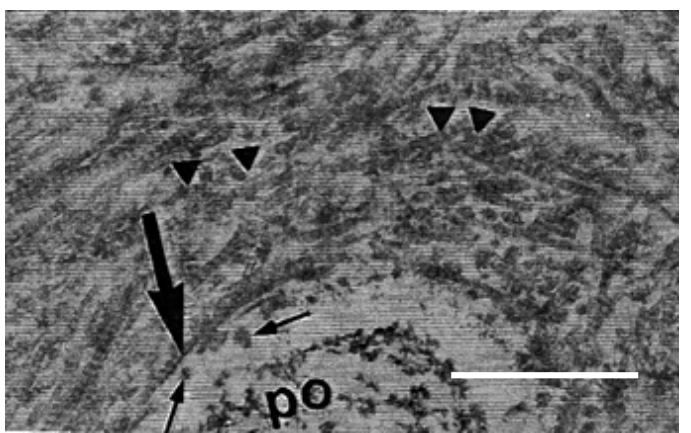

Fig. (5A). Transmission electron micrograph of rat molars. In GI molars, odontoblastic processes (op) were detected in the interior of the dentin tubules. Some residual fibrils (shorter arrows) were noted in the periodontoblastic space. Concentric collagen fibrils (larger arrow) were observed in the peritubular dentin and surrounding the dentin tubules (arrowheads). (Calibration bar: $1 \mu \mathrm{m}$ ).

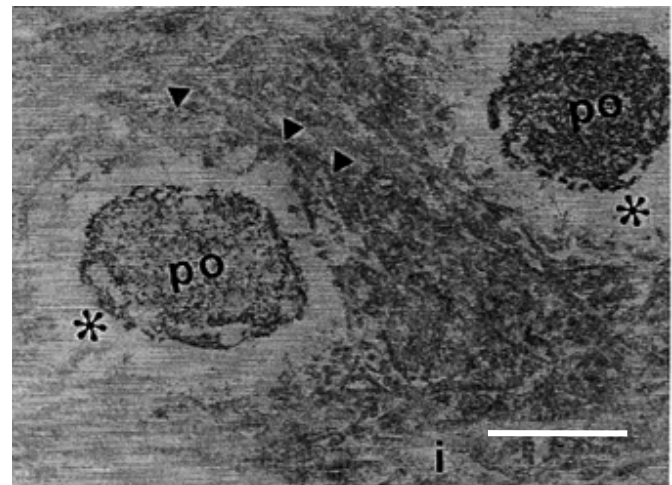

Fig. (5B). Transmission electron micrograph of rat molars. In GII molars, odontoblastic process (op), intertubular dentin (i), periodontoblastic space $\left(^{*}\right)$ were examined and collagen fibrils of the intertubular dentin exhibit differences (arrowheads) (Calibration bar: 1 $\mu \mathrm{m})$.

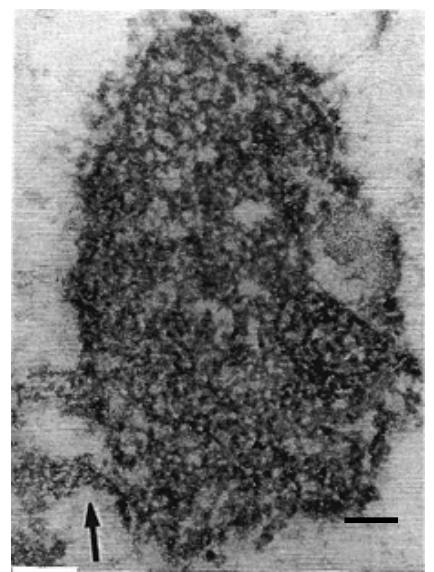

Fig. (5C). Transmission electron micrograph of rat molars. Within GI molars, odontoblastic process and residual fibrils (arrows) exhibited dense and homogeneous structure (Calibration bar:0, $1 \mu \mathrm{m}$ ).

\section{DISCUSSION}

To examine the effects of malnutrition in rat molar formation, we examined both external and ultra-structural morphological differences. Indeed, our results suggest that ex- trinsic factors, such as diet, can have a profound influence on tooth formation. Diet is thought to be important during two distinct stages of dental development [16]. During the preeruptive phase, nutrients are required for tooth maturation,

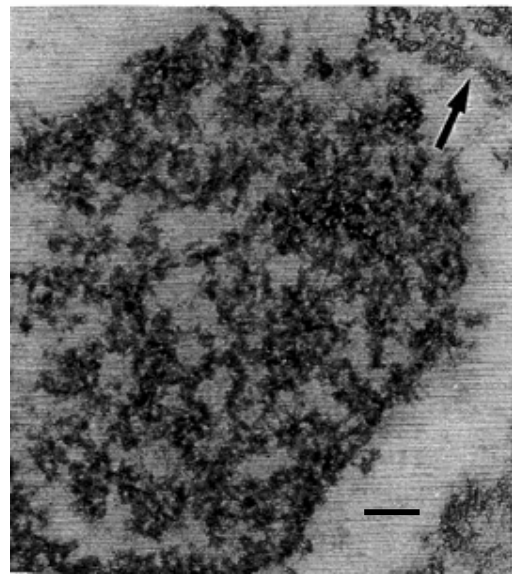

Fig. (5D). Transmission electron micrograph of rat molars. Within GII molars, the structure within the odontoblastic process appears less dense, and residual fibrils (arrows) can be detected (Calibration bar: $0,1 \mu \mathrm{m})$.

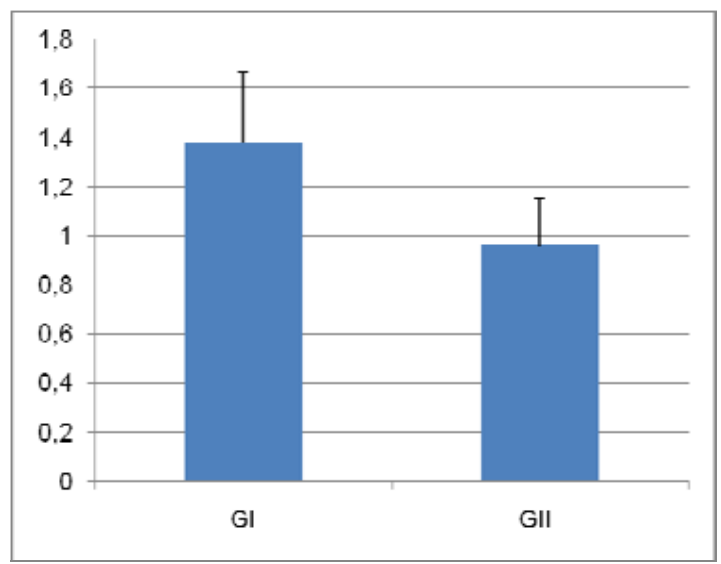

Fig. 6. Surface area of dentin sections of molars from both groups. Mean values and standard deviations are represented.

contributing to their chemical composition, and influencing size and morphology. In addition, once teeth are formed, although they are no longer structurally altered, dental structure can be strongly influenced during its formation period. Our results are consistent with this proposal, since experimental malnutrition was induced during the pre-eruptive phase of tooth development. It is likely that malnutrition led to a delay in the development of the dentin in GII animals, which exhibited a predominance of type III collagen fibers. This can lead to consequences not only for tooth formation, but also mineralization of dental structures [28], since the collagen framework is thought not to be a passive participant in mineralization, but may play a more active role $[10,12$, $14,29,30]$. Previous studies of development and eruption of teeth in a variety of species have led to a consensus regarding the role of nutrition in timing of the eruption process. Although our experiments were performed during weaning period, morphological differences in the teeth of GII is consistent with studies correlating malnutrition and dental abnormalities [11], as well as development of caries $[13,15]$. 
Malnutrition is also associated to deficiencies in the metabolism of the connective tissue [31]. As a result, a significant decrease in collagen synthesis, the main protein constituent of the tissues, is observed, leading in turn to changes in growth in various organs. Importantly, this has also been found to influence the dental germs of rats submitted to pre and postnatal protein deficiency [20]. Thus, a reduction in collagen synthesis may explain the decrease in dentin observed in GII animals. This is consistent with previously published results examining molars from rat pups whose mothers were submitted to a protein deficient diet during gestation and lactation [10]. Importantly, reduced tooth size in undernourished animals is thought to result from a decrease in the volume of the dentin rather than a reduction in the thickness of the enamel [10,22].

Protein deficiency led to smaller incisors than in the control animals [32]. Those authors suggested that the effect protein deficiency on dentin formation seems to be related to the predentin mineralization rates. Thus the odontoblasts, predentin and enamel appeared slower, but their ultrastructure were normal. Our results would appear to be at odds with some previously published reports. For example, protein deficiency later in development, led to no obvious differences in odontoblast structure [32]. In spite of this evidence, we observed irregular fibroblast morphology as well as its small and intensely stained nuclei in the teeth from the undernourished group, with malnutrition. These different results would be related to protein deficiency degree, because the authors [32] used protein deficiency later in development, during the 43rd day of life, and we verified this deficiency early, since the period of intra-uterine life until weaning. Moreover, cells within molars of the malnourished group appeared disorganized and non-palisade, in contrast with molars from the properly-nourished group. Disruption of the odontoblastic layer in GII may be responsible for the apparent decrease in the diameter and density of the collagen fibrils of the intertubular dentin.

Processes that affect collagen synthesis, such as protein or vitamin $\mathrm{C}$ deficiencies, can lead to periodontal ligament atrophy [33]. The irregularly arrayed collagen fibers of the periodontal ligament resulting from malnutrition, as well loss of epithelial adherence of the junctional epithelium are consistent with this proposal. The fibrilar part of this ligament has been reported to consist mainly of Type I collagen fibers [34], consistent with our findings. The clear prevalence of Type III collagen fibers in the malnourished group is therefore suggestive of immature periodontal ligaments, or delayed development in malnourished animals. The predominance of type III collagen in the alveolar bone in malnourished may also indicate a delay in tissue bone formation. This could result from a decrease in the osteoblastic activity, leading to a delay in the establishment of the ossification points. In fact, this phenomenon has been described in mandibles of rats submitted to protein and caloric deficiencies [7], and in humans $[12,15,30]$ that lives in underdevelopment countries. In some places of Africa, this situation tends to be much more serious, and the prevalent oral diseases include cancrum oris, acute necrotising gingivitis, oral cancer, oral manifestations of HIV/AIDS, facial trauma, and lastly dental caries [35].

\section{CONCLUSIONS}

Protein deficiency led to reduction of Type I collagen and an increase in Type III collagen fibers in the dentin, periodontal ligaments, and alveolar bone of rats. In addition, protein deficiency led to greatly reduced dentin formation. This study suggests that both structural and ultra-structural features of the dentin-pulp complex and periodontal components of rat molars are affected by protein levels.

\section{REFERENCES}

[1] Zeman FJ. Effect of the young rat of maternal protein restriction. J Nutr 1967; 93: 167-73.

[2] Gopinath G, Roy S, Karmarkar M. Effect of undernutrition and rehabilitation on the postnatal growth of skeletal muscle and nerve in the rat. Indian J Med Res 1983; 77: 702-12.

[3] Reichling TD, German RZ. Bones, muscles and visceral organs of protein-malnourished rats (rattus norvegicus) grow more slowly but for longer durations to reach normal final size. J Nutr 2000; 130: 2326-32.

[4] Fortman JK 2nd, Reichling T, German RZ. The impact of maternal protein malnutrition on pre-weaning skeletal and visceral organ growth in neonatal offspring of Rattus norvegicus. Growth Dev Aging 2005; 69: 39-52.

[5] Shrader RE, Zeman FJ. Skeletal development in rats as affected by maternal protein deprivation and postnatal food supply. J Nutr 1973; 103: 792-801.

[6] Alippi RM, Barcelo AC, Bardi M, Friedman SM, Rio ME, Bozzini CE. Effect of protein-free diet on growth of the skeletal units of the rat mandible. Acta Odontol Latinoamericana 1984; 1: 9-13.

[7] Naranjo AF, Landín FAC. Efectos de la desnutrición protéicocalórica en el crecimiento mandibular de las ratas. Rev Cuba Estomatol 1985; 22: 168-76.

[8] Alippi RM, Meta MD, Oliveira MI, et al. Effect of protein-energy malnutrition in early life on the dimensions and bone quality of the adult rat mandible. Arch Oral Biol 2002; 47: 47-53.

[9] Dreizen S. The importance of nutrition in tooth development. J Sch Health 1973; 43: 114-5.

[10] Holloway PJ, Shaw JH, Sweeney EA. Effects of various sucrose: casein ratios in purified diets on the teeth and supporting structures of rats. Arch Oral Biol 1961; 3: 185-200.

[11] Shaw JH, Griffiths D. Dental abnormalities in rats attributable to protein deficiency during reproduction. J Nutr 1963; 80: 123-41.

[12] Tie LT, Lian OK, Liong-Ong TW, Rose CS. Health, development and nutritional survey of preschool children in Central Java. Am J Clin Nutr 1967; 20: 1260-6.

[13] Menaker L, Navia JM. Effect of undernutrition during the perinatal period on caries development in the rat. IV. Effects of differential tooth eruption and exposure to a cariogenic diet on subsequent dental caries incidence. J Dent Res 1973; 52: 692-7.

[14] DiOrio LP, Miller SA, Navia JM. The separate effects of protein and calorie malnutrition on the development and growth of rat bones and teeth. J Nutr 1973; 103: 856-65.

[15] Alvarez JO, Caceda J, Woolley TW, et al. A longitudinal study of dental caries in the primary teeth of children who suffered from infant malnutrition. J Dent Res 1993; 72: 1573-6.

[16] Navia JM, DiOrio LP, Menaker L, Miller S. Effect of undernutrition during the perinatal period on caries development in the rat. J Dent Res 1970; 49: 1091-8.

[17] Alvarez JO, Lewis CA, Saman C, et al. Chronic malnutrition, dental caries, and tooth exfoliation in Peruvian children aged 3-9 years. Am J Clin Nutr 1988; 48: 368-72.

[18] Rugg-Gunn AJ. Nutrition, diet and dental public health. Commun Dent Health 1993; 10: 47-56.

[19] Nakamoto T, Mallak HM, Miller SA. The effect of protein-energy malnutrition on the growth of tooth germs in newborn rats. J Dent Res 1979; 58: 1115-22.

[20] Nakamoto T, Mallek HM, Miller SA. In vitro collagen synthesis of tooth germs from newborn rats with protein-energy malnutrition. J Dent Res 1979; 58: 1717-21.

[21] Maciejewska I, Adamowicz-Klepalska B, Kmiec Z, Dziewiatkowski J. Influence of diet and fluoride on dentin and enamel deposition and maturation in rats. Folia Morphol (Warsz) 2000; 59: 1316. 
[22] Huumonen S, Larmas M. Effects of protein deficiency induced by raw soy with and without sucrose on dentine formation and dentinal caries in young rats. Arch Oral Biol 2005; 50: 453-9.

[23] Chaves AM, Rosenblatt A, Oliveira OF. Enamel defects and its relation to life course events in primary dentition of Brazilian children: a longitudinal study. Commun Dent Health 2007; 24: 31-6.

[24] Reeves PG, Nielsen FH, Fahey GC Jr. AIN-93 purified diets for laboratory rodents: final report of the American Institute of Nutrition ad hoc writing committee on the reformulation of the AIN-76A rodent diet. J Nutr 1993; 123: 1939-51.

[25] Morse A. Formic acid-sodium citrate decalcification and butyl alcohol dehydration of teeth and bones for sectoring in paraffin. $\mathrm{J}$ Dent Res 1945; 24: 143-53.

[26] Junqueira LCU, Cossermelli W, Brentani R. Differencial staining of collagens type 1, 2 and 3 by sirius red and polarization microscopy. Arch Histol Jap 1978; 41: 261-74.

[27] Burke AP, Farb A, Tashko G, Virmani R. Arrhythmogenic right ventricular cardiomyopathy and fatty replacement of the right ventricular myocardium: are they different diseases? Circulation 1998; 97: $1571-80$.

[28] Beniash E, Traub W, Veis A, Weiner S. A transmission electron microscope study using vitrified ice sections of predentin: struc- tural changes in the dentin collagenous matrix prior to mineralization. J Struct Biol 2000; 132: 212-25.

[29] Garn SM, Russell AL. The effect of nutritional extremes on dental development. Am J Clin Nutr 1971; 24: 285-6.

[30] Delgado H, Habicht JP, Yarbrough C, et al. Nutritional status and the timing of deciduous tooth eruption. Am J Clin Nutr 1975; 28 : 216-24.

[31] Spanheimer R, Zlatev T, Umpierrez G, DiGigirolamo M. Collagen production in fasted and food-restricted rats: response to duration and severity of food deprivation. J Nutr 1991; 121: 518-24.

[32] Glick PL, Rowe DJ. Effects of chronic protein deficiency on the formation of the rat incisor teeth. Arch Oral Biol 1981; 26: 459-66.

[33] Avery JK. Oral development and histology. $3^{\text {rd }}$ ed. New York, USA: Thieme Medical Publishers 2002; p. 435.

[34] Katchburian E, Arana-Chavez VE. Histologia e Embriologia Oral. $2^{\text {nd }}$ ed. Rio de Janeiro: Pamericana - Guanabara Koogan 2004; p. 388.

[35] Thorpe SJ. Development of oral health in Africa. Med Princ Pract 2003; 12: 61-64.

(c) Gonçalves et al.; Licensee Bentham Open.

This is an open access article licensed under the terms of the Creative Commons Attribution Non-Commercial License (http: //creativecommons.org/licenses/ by-nc/3.0/) which permits unrestricted, non-commercial use, distribution and reproduction in any medium, provided the work is properly cited. 